\title{
'FOUR GOALS FOR THREE PLAYERS': USING 3 VS. 3 SMALL-SIDED GAMES AT SCHOOL
}

original paper

( ) University School of Physical Education in Wroclaw

DOI: https://doi.org/10.5114/hm.2019.85096

\section{CARLOS EVANGELIO ${ }^{1}$, MANUEL JACOB SIERRA-DÍAZ ${ }^{1}$, SIXTO GONZÁLEZ-VÍLLORA ${ }^{1}$, FILIPE MANUEL CLEMENTE ${ }^{2,3}$}

${ }^{1}$ Physical Education Department, Faculty of Education, University of Castilla-La Mancha, Cuenca, Spain

${ }^{2}$ School of Sport and Leisure, Polytechnic Institute of Viana do Castelo, Viana do Castelo, Portugal

${ }^{3}$ Instituto de Telecomunicações, Covilhã, Portugal

\section{ABSTRACT}

Purpose. Small-sided games (SSGs) are extensively used in soccer training around the world owing to the physical and physiological improvements reported among athletes. Elementary physical education students could achieve and solidify their tactical/technical knowledge in a relatively short time with the SSGs pedagogical strategy. The aim of this research was, firstly, to establish the between-age differences in the physical and physiological demands of a 3 vs. 3 futsal SSGs called 'four goals for three players,' and, secondly, to assess the tactical/technical knowledge acquisition.

Methods. The sample involved 57 students (aged $10.44 \pm 1.30$ years) from a Spanish primary state school, grades third to sixth (8-12 years of age). The Polar Team Pro ${ }^{\text {TM }}$ technology was used for collecting physical and physiological variables. The tactical/technical knowledge was evaluated with the Game Performance Assessment Instrument (GPAI) co-assessment throughout SSGs implementation. ANOVA tests were executed.

Results. Significantly different values were observed among different grades regarding the participants' average heart rate (bpm), minimum heart rate $(\mathrm{bpm})$, maximum speed $(\mathrm{km} / \mathrm{h})$, number of accelerations $\left(-1.99 ;-1.00 \mathrm{~m} / \mathrm{s}^{2}\right)$, number of accelerations $\left(-0.99 ;-0.50 \mathrm{~m} / \mathrm{s}^{2}\right)$, number of accelerations $\left(0.50 ; 0.99 \mathrm{~m} / \mathrm{s}^{2}\right)$, and number of accelerations $\left(1.00 ; 1.99 \mathrm{~m} / \mathrm{s}^{2}\right)$. The analysis of variance for GPAI scores revealed significantly greater values only among different grades for the implication of game and shot decision-making index.

Conclusions. Physiological demands and tactical/technical knowledge are also observed in educational context when SSGs are implemented. This pedagogical strategy helps teachers increase active participation during physical education sessions.

Key words: small-sided games, physical education, sports teaching process, futsal, game performance and sport assessment

\section{Introduction}

Physical education (PE) is a complex subject involving many topics related to physical activity, health, perception, orientation, motor skills, body language, or sports initiation. This fact implies, on the part of the teachers, an accurate elaboration of the lesson plans for each class and selection of the best teaching approach in accordance with the needs of the class [1].

Regarding the introductory stage of sports learning specifically, the modified games could provide a methodological approach that guarantees that stu- dents develop significant tactical/technical knowledge about sports in a relatively short period [2]. These kinds of games change and simplify some features of a real sport (the number of players, the length of the field, the time of play, and/or the basic rules of the game) to facilitate its learning process. When these basic features are significantly reduced, modified games are referred to as small-sided games (SSGs) [3]. It is observed that SSGs optimize, firstly, the physical and physiological aspects and, secondly, the cognitive demands of sports instead of replicating the play of a real match, which is more complex [4-6]. Indeed,

Correspondence address: Sixto González-Víllora, Edificio Fray Luis de León, Campus Universitario s/n (16071), Cuenca, Spain, e-mail: sixto.gonzalez@uclm.es

Received: January 24, 2019

Accepted for publication: April 26, 2019

Citation: Evangelio C, Sierra-Díaz MJ, González-Víllora S, Clemente FM. 'Four goals for three players': using 3 vs. 3 small-sided games at school. Hum Mov. 2019;20(4):68-78; doi: https://oi.org/10.5114/hm.2019.85096. 
these games are widely used as a tool that provides tactical/technical knowledge while significantly increasing player participation; therefore, the use of the term 'small-sided and conditioned games' is proposed to reinforce the idea of training-specific tactical/technical behaviours [7].

Firstly, most of the recent research focuses on observing the significant physical and physiological benefits derived from the implementation of SSGs in high-performance contexts [8], and new studies related to SSGs implementation in PE classes in elementary and secondary school are needed [9]. In the school context, SSGs are included in some pedagogical models, especially in the game-centred approach [10]. Consequently, the analysis of the tactical/technical knowledge and the internal (i.e. heart rate [HR]) and external (i.e. distance travelled) loads among students is a complex process because of SSGs included inside a holistic approach (e.g. pedagogical models) [11]. This indicates that teachers should not be focused only on students' demands but also on the methodological aspects, such as the type of sport, the group organization, or the methods used to motivate pupils, among others.

With regard to the external load, according to RojasInda [12], the use of technology (such as the Global Positioning System [GPS] devices and accelerometers) allows for more complete, objective, and complex assessments of training external load, too. Therefore, teachers and trainers could adapt and modify SSGs depending on the physiological needs of their students or players. Consequently, many manufacturers of athlete-tracking devices now exist, providing a wide range of chip-sets and data-processing algorithms [13]. Nevertheless, there is currently no reporting standard for using this kind of devices in sports and educational research, and their validation and reliability should be ensured before implementing any modifications in the class or in high-performance training [14]. In contrast, it is observed that the real-time data of the external and internal loads, as well as the clarity of the filters and algorithms used to execute these data in a 'friendly' way could help teachers to design more enriching sessions, optimizing the performance and the level of knowledge of students and players [15].

As for the internal load, Holf et al. [16] confirmed that $\mathrm{HR}$ values (i.e. maximum, average, minimum) are valid, reliable, and objective indicators of a player's performance and intensity. In an SSG training context, Owen et al. [17] reported that there was a significant increase in $\mathrm{HR}$ values in a 3 vs. 3 SSGs (i.e. a game with 3 participants in each team) when compared with SSGs which contained more than 3 players in each team. This fact, together with the idea that the distance travelled increases during the implementation of SSGs rather than other kind of traditional games [5], reinforce the concept that SSGs increase highperformance players' aerobic capacity.

In addition, there is another important variable related to the number of participants widely investigated in soccer: the area of the game. Atl et al. [18] ensured that physiological levels increased when the area of the playing field used in an SSG was large. However, they also observed that the number of passes and the number of technical actions performed increased significantly when the area of the pitch was medium, as was the case in a recent study among participants from elite soccer schools [19] where players' physical performance increased in SSGs played on large pitches, but ball possession duration and shot attempts were significantly influenced in large games.

Secondly, another important aspect of SSGs is the tactical/technical knowledge gained. It has been often observed that the SSG formats help players to achieve enough cognitive development to 'read' the game and to select the best skill (decision-making competence) in order to solve a tactical problem during both SSGs and real matches. According to Serra Olivares et al. [20], players should try to search for relevant solutions to the tactical/technical problems of the game starting with the first tactical principles proposed by Bayer [21]: keep possession of the ball. This implies a greater number of movements to empty spaces into the area during SSGs and a consequent increase in physiological demands. Thus, SSGs seem to increase the responses placed on players because they are presented as contextualized and meaningful games, in contrast to isolated technical drills.

Even though tactical/technical concepts could be easily explained to young elite players in a single training session, this knowledge should be introduced to elementary school students in a progressive way through the pedagogical model selected, following the tactical principles proposed by Bayer [21]. Moreover, the findings regarding SSGs effects on soccer participants' responses $[16,17]$ are not demonstrated in PE students [9]. Indeed, it is important to know whether SSGs can become an important alternative strategy of eliciting conditions to contribute to appropriate physical, cognitive, and social improvements in PE classes for the medium and long term, both in school and out of school, as has been demonstrated in high-performance contexts [3, 13].

For all these reasons, the aim of this article was to analyse the effects and effectiveness of implementing 
futsal SSGs in a Spanish primary state school as a contextualized teaching/learning tool that enables students to increase their performance, as well as to compare the tactical/technical knowledge acquisition with the use of the Game Performance Assessment Instrument (GPAI) co-assessment among different grades (third to sixth). The hypothesis poses that the use of SSGs in an educational context will improve the positive effects of the main physiological demands, and the tactical/technical aspects in the later grades (fifth/sixth).

\section{Material and methods}

\section{Participants and main features}

Overall, 57 students from a Spanish primary state school were tested. As can be observed in Table 1, $30 \%$ of that sample ( $n=17)$ was from the third grade, $23 \%(n=13)$ was from the fourth grade, $24 \%(n=14)$ was from the fifth grade, and $23 \%(n=13)$ was from the sixth grade. Besides, $52.60 \%(n=30)$ were male students, and $47.40 \%(n=27)$ were female students.

Before starting the study, as shown in Table 2, students' height and weight were measured by using a stable stadiometer SECA ${ }^{\mathrm{TM}}$ (model 217) and TANITA ${ }^{\mathrm{TM}}$ (model DC-430 MA), respectively. Later, a questionnaire asking about the participants' socioeconomic status and physical activity lifestyle variables was administered to ascertain the degree of physical and sports practice in the extracurricular context, as well as the variables influencing the degree of practice. The questionnaire included variables related to the socioeconomic level (low, medium, or high) and the educational level of the parents (primary, secondary, degree, master's, or $\mathrm{PhD}$ ). In terms of the physical activity lifestyle variables, the questionnaire referred to the participants' favourite sports, the frequency at which they practised sports (including the time spent practising at school), and the type of extracurricular activities performed, as well as time spent playing computer games and watching television per week.
Although $63.3 \%$ of boys were familiar with soccer, Cronbach's alpha showed large consistency and reliability in physical $(\alpha=0.80)$ and tactical/technical variables $(\alpha=0.86)$. This coefficient guarantees that the group heterogeneity at the initial levels of content knowledge and competence does not significantly influence the results. Finally, a multistage $20-\mathrm{m}$ shuttle run test was also implemented to determine the maximum HR and the maximum $\mathrm{VO}_{2}$ of each student; these variables were measured with the Polar Team $\mathrm{Pro}^{\mathrm{TM}}$ technology.

\section{Study design}

A descriptive and quantitative quasi-experimental study design was applied. The intervention lasted 1 month, during which several futsal SSGs (mainly 3 vs. 3 and similar) were implemented. However, the 3 vs. 3 futsal SSGs called 'four goals for three players' were employed specifically in order to assess the physiological and tactical/technical demands that these features of the game impose on students and, consequently, to achieve the purpose of the present study.

As shown in Figure 1, this SSG is played on a pitch with the dimensions of $18 \times 14 \mathrm{~m}$. The aim of the game is to score a point in any of the 4 goals. Each goal has $3.5 \mathrm{~m}$ and is placed on the short side $(14 \mathrm{~m})$ of the pitch. The height of the goal is the average height of the players with the hands raised. The reason why there is one more goal than there are participants in one team is to highlight the third tactical attack principle proposed by Bayer [21]: to achieve a goal. In fact, this SSG also helps to consolidate the 3 Bayer's attack principles for the introductory stage of sports learning [21].

However, adaptations are needed to achieve the maximal benefits, such as shooting being allowed only when all 3 players have held or controlled the ball and when they have trespassed the 'allowed shooting' line (which reinforces the active participation of every student). Each game lasts 5 minutes in one isolated period; there are no goalkeepers.

The independent variables were the academic

Table 1. Main features of the sample and distribution by grade and gender

\begin{tabular}{lccccccc}
\hline \multirow{2}{*}{ Grade } & Average age (years) & \multicolumn{5}{c}{ Distribution in the class } \\
\cline { 3 - 7 } & & \multicolumn{2}{c}{ Male } & \multicolumn{2}{c}{ Female } & \multicolumn{2}{c}{ Total } \\
\hline Third & $8.96 \pm 0.43$ & $17.50 \%$ & $n=10$ & $12.30 \%$ & $n=7$ & $29.80 \%$ & $n=17$ \\
Fourth & $10.10 \pm 0.63$ & $10.50 \%$ & $n=6$ & $12.30 \%$ & $n=7$ & $22.80 \%$ & $n=13$ \\
Fifth & $10.91 \pm 0.28$ & $12.30 \%$ & $n=7$ & $12.30 \%$ & $n=7$ & $24.60 \%$ & $n=14$ \\
Sixth & $12.23 \pm 0.46$ & $12.30 \%$ & $n=7$ & $10.05 \%$ & $n=6$ & $22.80 \%$ & $n=13$ \\
Total & $10.44 \pm 1.30$ & $52.60 \%$ & $n=30$ & $47.40 \%$ & $n=27$ & $100 \%$ & $n=57$ \\
\hline
\end{tabular}


Table 2. Descriptive physical characteristics of each grade

\begin{tabular}{|c|c|c|c|c|c|c|}
\hline \multirow{3}{*}{ Grade } & \multirow{3}{*}{ Height (cm) } & \multirow{3}{*}{ Weight (kg) } & \multicolumn{3}{|c|}{ Physical activity and sport questionnaire } & \multirow{3}{*}{$\begin{array}{l}\text { Maximum HR } \\
(\mathrm{bpm})\end{array}$} \\
\hline & & & \multicolumn{2}{|c|}{ Favourite sport } & \multirow{2}{*}{$\begin{array}{c}\text { Time } \\
\text { of practice } \\
\text { (years) }\end{array}$} & \\
\hline & & & Male & Female & & \\
\hline Third & $134.06 \pm 7.18$ & $31.76 \pm 6.54$ & Soc. $(60 \%)$ & Gymn. (42.9\%) & $3.24 \pm 1.34$ & $190.35 \pm 17.44$ \\
\hline Fourth & $139.15 \pm 5.58$ & $39.85 \pm 5.16$ & Soc. $(50 \%)$ & Gymn. (42.9\%) & $3.62 \pm 1.38$ & $183.69 \pm 20.97$ \\
\hline Fifth & $141.93 \pm 4.44$ & $42.86 \pm 8.69$ & Soc. $(85.7 \%)$ & Gymn. $(28.6 \%)$ & $3.36 \pm 1.55$ & $190.07 \pm 11.39$ \\
\hline Sixth & $148.62 \pm 8.54$ & $44.38 \pm 6.92$ & Soc. $(51.7 \%)$ & Dan. $(50 \%)$ & $3.23 \pm 1.73$ & $198.38 \pm 11.39$ \\
\hline Total & $140.47 \pm 8.39$ & $39.21 \pm 8.49$ & Soc. $(63.3 \%)$ & Gymn. (37\%) & $3.35 \pm 1.47$ & $190.60 \pm 16.98$ \\
\hline
\end{tabular}

Dan. - dancing, Gymn. - gymnastics, Soc. - soccer

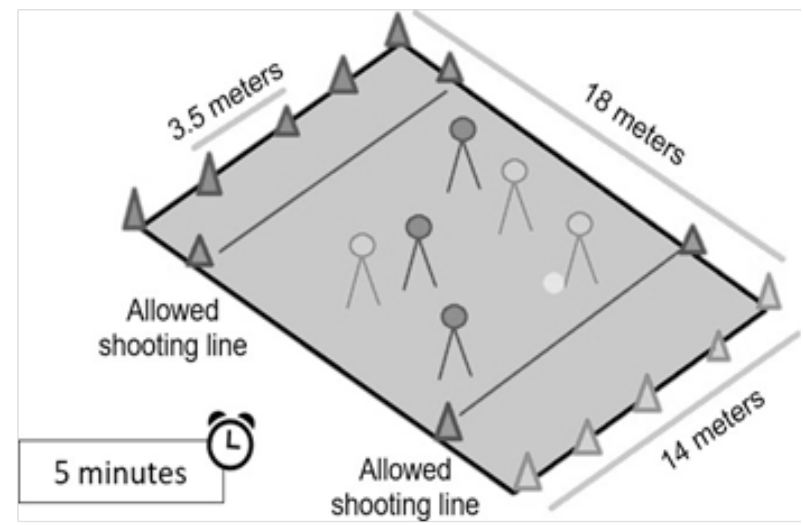

Figure 1. The SSG 'four goals for three players'

grade in PE (third, fourth, fifth, and sixth) and the age of the students. The dependent variables were, on the one hand, the variables related to the physiological aspects of each student registered by the Polar Team Pro $^{\text {TM }}$ technology, which included HR information, distance travelled, number of accelerations, and number of sprints. On the other hand, the factors related to GPAI [22], which involved decision-making and the technical execution of passes, (ball) receptions, shots and drives indices, game performance index, and implication of the game index, were also dependent variables.

Each grade played the 3 vs. 3 futsal SSG 'four goals for three players' 3 times during PE sessions at the sports centre next to the school during the 20162017 academic year. Owing to the administration of the academic time in the school and other programmed activities, $26.30 \%$ of students $(n=15)$ repeated their participation in other games in their respective grade.

\section{Instruments}

In order to collect data for the variables mentioned above, they were classified into 2 categories: physio- logical responses and tactical/technical knowledge. The instruments described below were used to collect the data.

The Polar Team Pro ${ }^{\mathrm{TM}}$ hardware and software (Polar Electro, Finland) were employed in order to register, in an objective way, all the physiological aspects related to each player [14]. This technology included (i) a Polar Team Pro Sensor, which incorporated an integrated GPS $(10 \mathrm{~Hz})$, and 3 microelectrical mechanical system components (accelerometer, gyroscope, and digital compass $200 \mathrm{~Hz}$ ); the sensor was used with the Polar Team Pro soft strap, the total weight of which was $60 \mathrm{~g}$; (ii) a set of sensors with a lithium polymer rechargeable battery station (Polar Team Pro DockTM); (iii) the Polar Team Pro App ${ }^{\mathrm{TM}}$, compatible with $\mathrm{iPad}^{\mathrm{TM}}$, which enabled the collection of the real-time data of each player. It was possible to extract the following variables by using the system: maximum, minimum, and average HR (measured in beats per minute [bpm]); distance travelled (measured in $\mathrm{km}$ ); distance in each speed zone (measured in $\mathrm{km} / \mathrm{h}$ ); number of accelerations (measured in $\mathrm{m} / \mathrm{s}^{2}$ ); number of sprints; or the maximum speed threshold $(2.8 \mathrm{~km} / \mathrm{h})$.

The GPAI co-assessment through recording event format evaluated the tactical/technical aspects of each participant during the SSGs [22]. This tool included (i) a reference chart to understand which aspects of students must be observed; and (ii) a registration sheet of each player's movement observed. The instrument focused on the attack phase - particularly decision-making and the technical execution of the passes, receptions, shots, and drives. In the registration sheet, observers were instructed to mark with a cross correct and incorrect decisions made as well as the execution of passes, receptions, shots, and drives made by the player during the game. The reference chart is the rubric that contains the most important elements that must be taken into account during the game performance (e.g., a correct shot decision-making is when 


\section{HUMAN MOVEMENT}

C. Evangelio et al., 3 vs. 3 small-sided games at school

the player has trespassed the 'allowed shooting' line and has an opportunity to score in any of the 4 goals as there is no player between the ball and the target goal; a correct shot technical execution is when the player has achieved the goal). At the end of the game, observers counted the total decisions and execution actions. Finally, with the use of specific formulas, the index of the correct and incorrect decisions made for every action was calculated. Moreover, some aspects of the active defence were observed. Each game was recorded with a Nikon ${ }^{\mathrm{TM}}$ camera (D5200). Subsequently, each SSG videotaping was reviewed by 3 experts with more than 10 years of research experience in team sport evaluation, especially using GPAI. The Cronbach's alpha value $(\alpha=0.86)$ indicated high reliability among students and evaluators.

\section{Statistical procedures}

The Kolmogorov-Smirnov test confirmed the normal distribution of the data $(p>0.05)$. An analysis of variance (ANOVA) and Bonferroni post-hoc test of the dependent variables were applied with the Statistical Package for the Social Sciences $\left(\right.$ SPSS $^{\mathrm{TM}}$ ), version 22. The $d$-Cohen effect size [23] was also calculated, with 0.20 considered a small effect, 0.50 a medium effect, 0.80 a large effect, and 1.30 a very large effect.

\section{Ethical approval}

The research related to human use has complied with all the relevant national regulations, organic laws in force, and institutional policies, has followed the tenets of the Declaration of Helsinki, and has complied with the ethical standards of the Faculty of Education of Cuenca (University of Castilla-La Mancha).

\section{Informed consent}

Informed consent has been obtained from the parents or legal guardians of all individuals included in this study, as well as from the PE teacher and the principal of the school.

\section{Results}

Firstly, in order to illustrate the general trend, Figure 2 shows the descriptive data for the most important variables obtained by the Polar Team $\mathrm{Pro}^{\mathrm{TM}}$ technology: the HR and the distance travelled by academic grade. It is observed that the fourth grade obtained the lowest scores for both average HR and total distance travelled.

In turn, Figure 3 presents the most important means related to the tactical/technical variables collected by the GPAI co-assessment process: the implication of the game index and the game performance index. It is observed that the participants in the fifth grade achieved the highest game performance score. It is also shown that participants in the fifth and sixth grades obtained the highest scores in the implication of the game index.

Table 3 shows that the ANOVA and Bonferroni post-hoc test related to physiological aspects showed significantly great differences for (i) minimum HR (measured in bpm) between third and fourth grade students (26\% [133-107]; $p=0.04 ; d=1.1)$, as well as between fourth and sixth grade students $(32 \%$ [107-139]; $p=0.01 ; d=1.4$ ), which both have a very large effect size; (ii) average HR (measured in bpm) between fourth and sixth grade students (26\% [178174 ]; $p=0.003 ; d=1.60$ ); and (iii) maximum speed (measured in $\mathrm{km} / \mathrm{h}$ ) between third and sixth grade
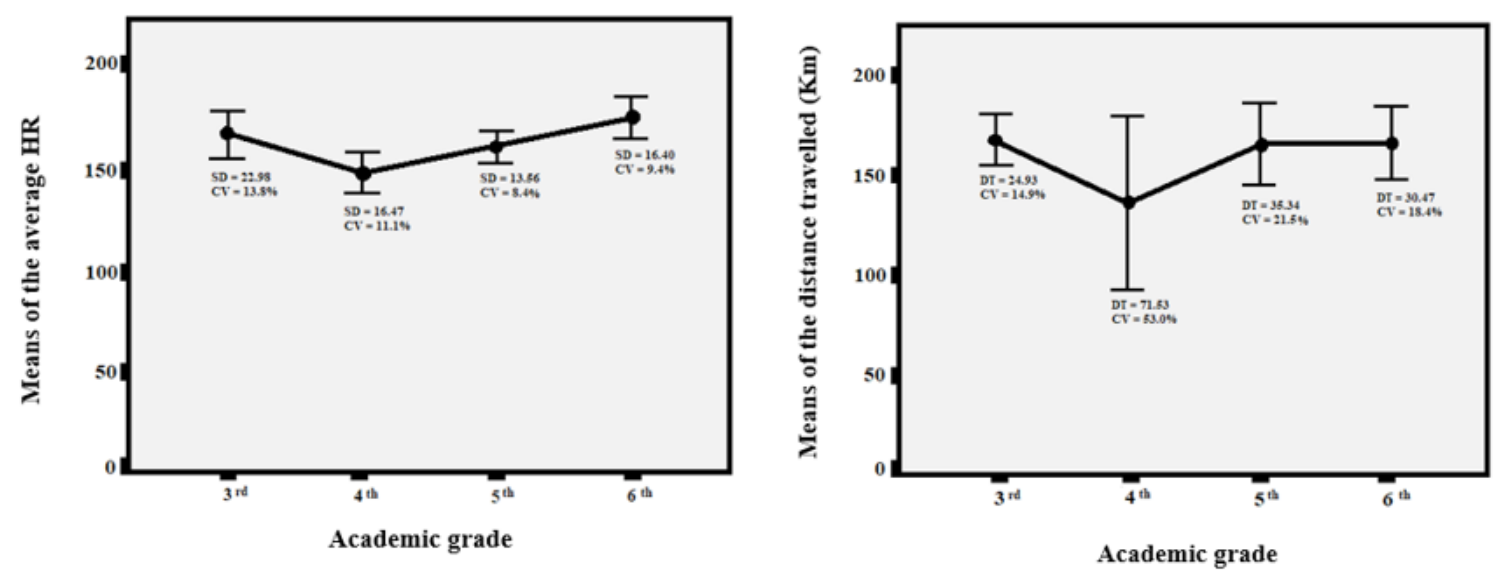

SD - standard deviation, CV - coefficient of variance, DT - distance travelled

Figure 2. Means of the most important variables collected by Polar Pro ${ }^{\mathrm{TM}}$ 

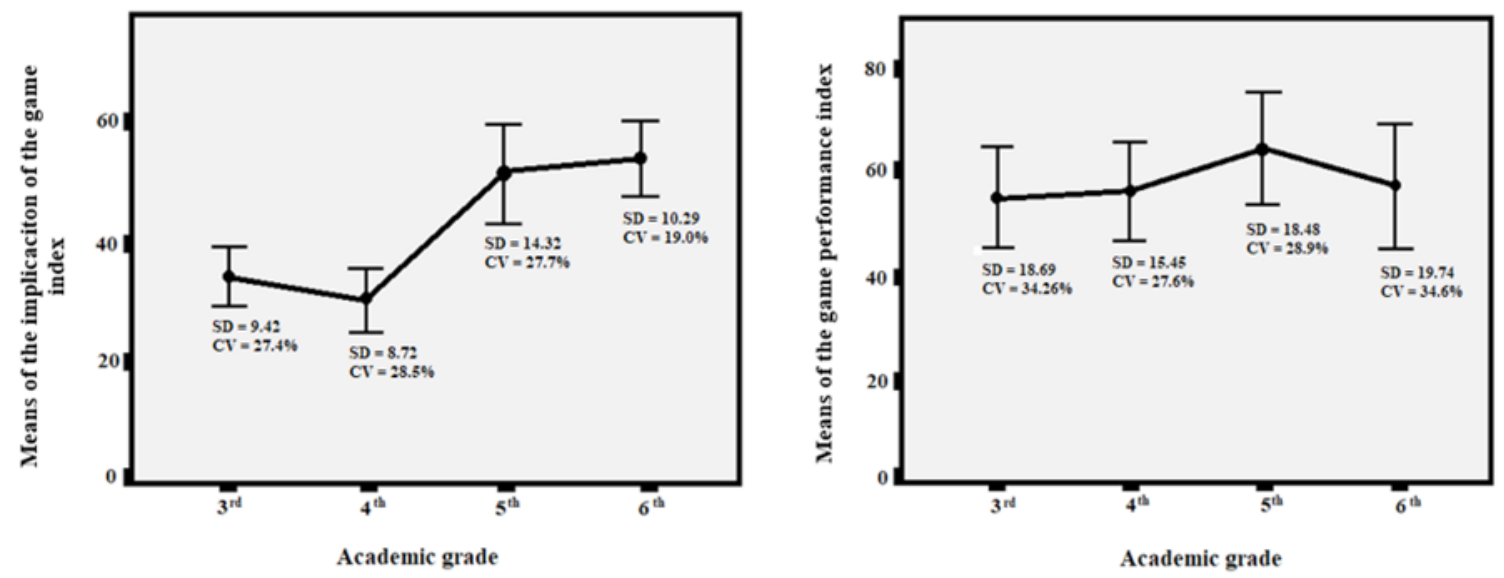

SD - standard deviation, CV - coefficient of variance

Figure 3. Means of the implication of the game and the game performance indices collected by GPAI

students (3\% [9-12], $p=0.02 ; d=1.01)$, as well as between fourth and sixth grade students $(4 \%$ [8-12]; $p=0.007 ; d=1.90$ ).

The results also show significantly great differences for (iv) the number of accelerations for several sectors: in the $(-1.99)-(-1.00) \mathrm{m} / \mathrm{s}^{2}$ sector between third and fourth grade students $(10 \%$ [21-11]; $p=$ $0.004 ; d=1.24)$, as well as between fourth and fifth grade students (10\% [11-21]; $p=0.005 ; d=1.35)$; in the $(-0.99)-(-0.50) \mathrm{m} / \mathrm{s}^{2}$ sector between third and fourth grade students (18\% [59-41]; $p=0.001 ; d=1.39$ ), between third and sixth grade students $(15 \%$ [59$44] ; p=0.01 ; d=1.10$ ), and between fourth and fifth grade students (16\% [41-57]; $p=0.008 ; d=1.50)$; in the $0.50-0.99 \mathrm{~m} / \mathrm{s}^{2}$ sector between third and fourth grade students (21\% [60-39]; $p \leqslant 0.001 ; d=1.60$ ), between third and sixth grade students (15\% [60-45], $p=0.007, d=1.09$ ), and between fourth and fifth grade students (18\% [39-57]; $p=0.001 ; d=2.07)$; and, finally, in the $1.00-1.99 \mathrm{~m} / \mathrm{s}^{2}$ sector between third and fourth grade students (8\% [19-11]; $p=0.02 ; d=$ 0.90). It was observed that the majority of Cohen's $d$ values showed a very large effect size.

Table 4 presents that the ANOVA and Bonferroni post-hoc tests related to the tactical/technical aspects assessed by GPAI revealed significantly great differences only for (i) the implication of the game index and (ii) the shot decision-making index. In re-

Table 3. Averages and standard deviations of significant physiological aspects in particular grades

\begin{tabular}{lccccc}
\hline Aspects & $\begin{array}{c}\text { Third } \\
n=17\end{array}$ & $\begin{array}{c}\text { Fourth } \\
n=13\end{array}$ & $\begin{array}{c}\text { Fifth } \\
n=14\end{array}$ & $\begin{array}{c}\text { Sixth } \\
n=13\end{array}$ & $\begin{array}{c}\text { Total } \\
n=57\end{array}$ \\
\hline Minimum HR (bpm) & $132.7(25.1)^{*}$ & $107.1(20.6)^{*}$ & $120.1(29.4)$ & $138.7(24.0)^{*}$ & $125.1(27.1)$ \\
Average HR (bpm) & $166.0(22.9)$ & $147.9(16.4)^{*}$ & $159.9(13.5)$ & $174.3(16.4)^{*}$ & $162.2(19.9)$ \\
Maximum speed (km/h) & $8.8(1.5)^{*}$ & $8.0(2.0)^{*}$ & $10.0(3.6)$ & $12.2(4.4)^{*}$ & $9.7(3.3)$ \\
Acc. (-1.99)-(-1.00) m/s $\mathrm{s}^{2}$ & $20.8(8.3)^{*}$ & $11.3(6.8)^{*}$ & $20.9(7.1)^{*}$ & $17.6(4.8)$ & $18.0(7.8)$ \\
Acc. (-0.99)-(-0.50) m/s $/ \mathrm{s}^{2}$ & $59.4(15.9)^{*}$ & $41.2(9.5)^{*}$ & $57.3(10.7)^{*}$ & $44.3(10.8)^{*}$ & $51.3(14.4)$ \\
Acc. 0.50-0.99 m/s & $60.1(16.3)^{*}$ & $38.9(1.1)^{*}$ & $56.7(7.9)^{*}$ & $45.2(10.3)^{*}$ & $51.0(14.3)$ \\
Acc. 1.00-1.99 m/s $/ \mathrm{s}^{2}$ & $19.0(8.3)^{*}$ & $11.4(8.3)^{*}$ & $17.7(5.8)$ & $14.3(2.5)$ & $15.9(7.3)$ \\
\hline
\end{tabular}

HR - heart rate, bpm - beats per minute, Acc. - acceleration

* significant differences between grades, $p<0.05$

Table 4. Averages and standard deviations of significant tactical/technical aspects in particular grades

\begin{tabular}{llcccc}
\hline Aspects & $\begin{array}{c}\text { Third } \\
n=17\end{array}$ & $\begin{array}{c}\text { Fourth } \\
n=13\end{array}$ & $\begin{array}{c}\text { Fifth } \\
n=14\end{array}$ & $\begin{array}{c}\text { Sixth } \\
n=13\end{array}$ & $\begin{array}{c}\text { Total } \\
n=57\end{array}$ \\
\hline Implication of the game & $34.3(9.4)^{*}$ & $30.5(8.7)^{*}$ & $51.5(14.3)^{*}$ & $53.9(10.2)^{*}$ & $42.1(14.7)$ \\
Shot decision-making & $18.6(14.2)$ & $15.1(12.5)^{*}$ & $46.5(37.5)^{*}$ & $45.0(35.5)^{*}$ & $30.8(25.5)$ \\
\hline
\end{tabular}

* significant differences between grades, $p<0.05$ 
lation to the implication of the game index, significant differences were observed between third and fifth grade students ( $42 \%$ [5-47]; $p=0.009 ; d=1.47)$ and between fourth and sixth grade students $(40 \%$ [5-45]; $p=0.01 ; d=1.49$ ). Both results show a large effect size. Regarding the shot decision-making index, significant differences were found between third and fifth grade students $(18 \%$ [34-52]; $p \leq 0.001 ; d=1.42)$, between third and sixth grade students (20\% [34-54]; $p \leqslant 0.001 ; d=1.98)$, between fourth and fifth grade students (21\% [31-52]; $p \leq 0.001 ; d=1.77)$, and between fourth and sixth grade students (23\% [31-54], $p \leq 0.001 ; d=2.45$ ). Cohen's $d$ values show very large and significant effect sizes in every index.

\section{Discussion}

The hypothesis of the investigation, which posits that SSGs in an educational context will enhance the effects of the main physiological and cognitive demands among the latest grades, is partially verified. The SSGs are an efficient method for developing physiological skills, tactical/technical knowledge, and social behaviours [5] in PE context.

Concerning the physical and physiological demands, statistically significant differences were found in HR among the different grades, particularly when comparing students in the third and sixth grades, which remains in line with what Cordova et al. [24] observed previously: physiological adaptations, such as $\mathrm{HR}$, increased during the implementation of SSGs. In contrast to the study by Atll et al. [18], HR was significantly higher among participants who played on a small pitch because the number of passes, receptions, and drives increased. Similar results were observed in a study conducted by Dellal et al. [25], in which HR responses were alike for amateur and professional soccer athletes. This fact, together with the results of the present study, these data demonstrate that the use of SSGs is a beneficial strategy to increase physiological responses in both PE classes, specifically at the introductory stage of sports learning, and elite training processes.

However, the results obtained in this study also support the observation of Hill-Haas et al. [26] that the physiological intensity could vary depending on the encouragement given by the teacher in relation to the plan of the sessions. This fact explains why significant differences were observed in HR responses between students from the third grade to the sixth grade. Although each team was encouraged with positive feedback during the game, more game stops occurred dur- ing games played by students in the fourth and fifth grades owing to breaches of the game rules, such as shots taken before a player passed the 'allowed shooting' line.

Conversely, distance values varied depending on the role of the students (i.e. defenders and attackers). According to Serra Olivares et al. [20], players tend to find tactical/technical solutions during SSGs starting with the first tactical principle: conserve possession of the ball [21]. For that reason, the students from the oldest grade tried to make more smart movements to empty spaces. This produces an increase in the distance travelled, in a similar way to the result observed in a previous study by Clemente et al. [5], in which distances travelled increased during SSGs.

Rojas-Inda [12] ensured that the physiological charge should be measured by the distance travelled, the number of accelerations, and HR. Similar results regarding the number of accelerations were observed in the study of the aforementioned author. The significant results for the physiological aspects, which included the number of accelerations in several sectors among S17 players, suggested that the cognitive structures were further developed in these players than in younger participants $[12,26]$. In the present study, students from the later grades (fifth and sixth) achieved a more advanced cognitive structure than the other students analysed.

Additionally, significant values for the implication of the game were observed in a similar study [27]. The authors noted that students who practised sports as part of their extracurricular activities had more favourable results than those who did not. The significant differences regarding the implication of the game matrix could be explained by the time spent practising among fifth and sixth grade students, who gained more practice than third and fourth grade students owing to the greater level of experience they had acquired during their longer lives [3, 28]. Even though futsal is slightly different from soccer, this fact reinforces the idea that playing alternative sports in PE classes equalizes the skills of the students (because these are games that none of the students has practised before) and increases their motivation [29].

Finally, regarding to cognitive demands, significant differences were observed between shot decision-making indices. However, in a similar study carried out by Balakrishnan et al. [30], there were no significant differences found in the tactical/technical indices of GPAI. According to Serra-Olivares et al. [31], the differences in decision-making could be due to the influence of the context itself, as well as the relationship 
between players. Third and fourth grade students tend to shoot without an elaborate or proper strategy involving the rest of the team; they also shoot without a concrete objective or goal. This was in contrast to fifth and sixth grade students, who tried to shoot when they had a considerable opportunity to achieve a goal. In turn, Parlebas [32] estimated that the motor and cognitive interactions were widely related to the uncertainty of the game. In this sense, this author proposed the use of strategies that promote students' creativity and learning based on practice in a game which should not be strictly controlled by the teacher (e.g., force to use a specific type of pass during the game).

In conclusion, although this study has some limitations, such as the small sample size, and the inferences drawn here should be taken cautiously, we have confirmed the benefits of the use of SSGs in the teaching and learning process of any sport (especially in invasion games) encompassed inside pedagogical models [2].

In the future, it would be useful to analyse the tactical/technical aspects by using alternative validated instruments, such as the Game Performance Evaluation Tool (GPET) or the System of Tactical Assessment in Soccer (FUT-SAT), with a larger sample. Additionally, it would be recommended to measure and quantify the differences in physiological responses and tactical/technical aspects, including psychology variables, between male and female students.

\section{Practical applications}

The results obtained in this study empirically support the design of lesson plans for sports initiation in PE. In fact, the primary concern of teachers revolves around when the best time is for students to begin learning to play any given sport in PE classes. In the words of Práxedes Pizarro et al. [9], the teachinglearning process of invasion games could start from the third grade. This is because then pupils achieve a cognitive structure which allows them to understand and learn new tactical/technical aspects of any game.

In addition, it is necessary to analyse the intended objectives of PE classes, as well as the characteristics of the students and the context of the class in order to select the best SSG format. Figure 4 shows that there are multiple variables that can be modified to adapt SSGs to the level of each student, as well as to achieve greater benefits than can be obtained through traditional sessions in a relatively short period [7].

As observed in Figure 4, the variables present in SSGs could be divided into 4 categories. The first one, players, is related to the number of students in each team. This is, in turn, associated with the size of the game zone. According to Clemente [3], there should be a relationship between the number of participants and the size of the playing area relative to the size of the 'personal area' of each player. For instance, if there are 3 or 4 participants in each team, the 'personal area' for each player should be set as 50-100 $\mathrm{m}^{2}$. Additionally, Kirk et al. [11] do not recommend more than 5 participants per team in PE context.

In this regard, when teachers decide to use this kind of game format in the classroom, they should be aware of the kind of sport and the tactical/technical aspects they want their students to develop. Thus, the sport variable determines the kind of SSG employed. Moreover, as demonstrated earlier, alternative sports or games help to equalize the skill levels among students [11].

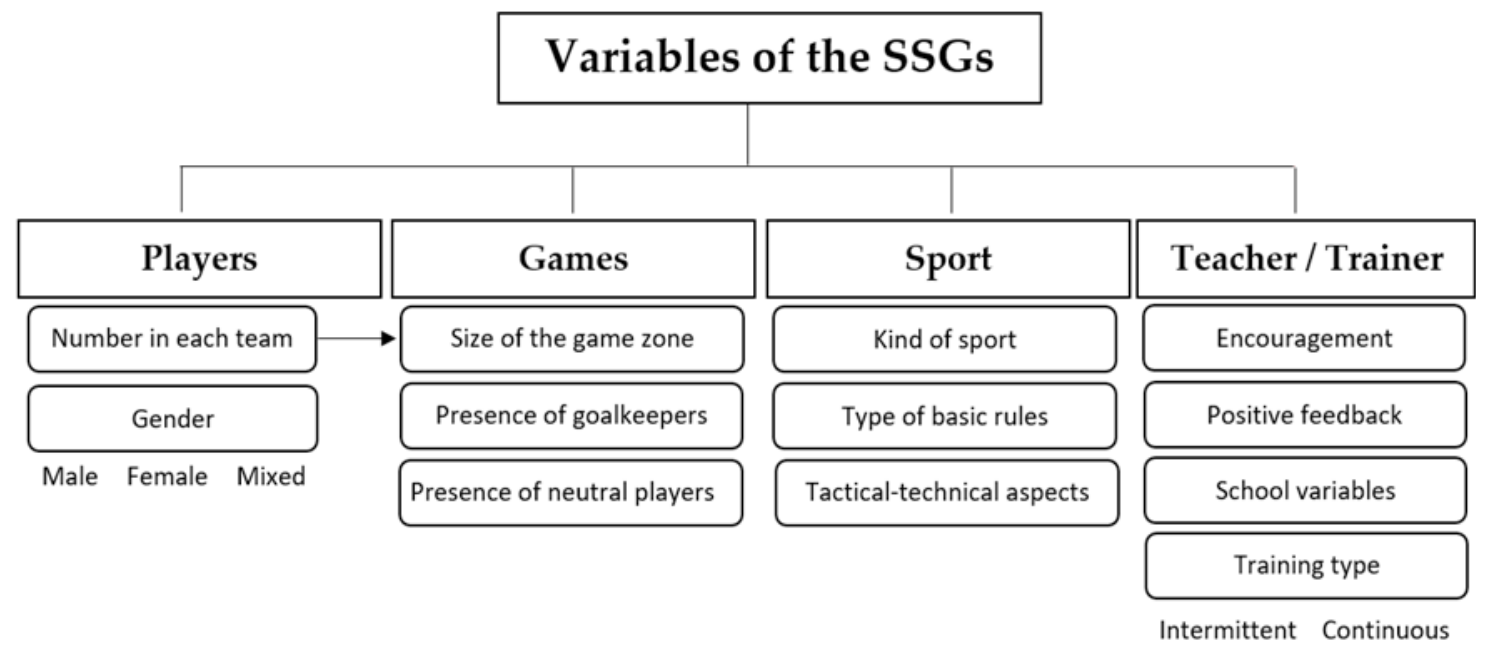

Figure 4. Variables of invasion small-sided games (SSGs) that help to adapt the sessions at the introductory stage of sports learning 
Finally, an important variable is the teacher or trainer. Engaging in intrinsic motivation during practice will increase the time of practice and the tactical/technical knowledge obtained. For that reason, giving positive feedback during the game is essential to create a positive atmosphere. In this sense, if students perceive improvements in their abilities (i.e. competence), their intrinsic motivation will rise and, consequently, their physical and sports practice will be also increased. However, within the educational context, there exist alongside other important variables that teachers have to deal with, such as rigorous timetables, assessments, and heterogeneous students.

In terms of evaluation, it is recommended that a coassessment process is implemented, using, for example, GPAI [22]. This helps students to focus on the most important decision-making and technical execution content for better performance. According to Aguilar Sánchez et al. [33], this tool is widely used and convenient in educational and extracurricular team sport context. In addition, Oslin et al. [22] and Balakrishnan et al. [30] highlighted the transferability of the tactical and technical knowledge among sports with similar features (e.g. specific materials, area, or objectives of the game). However, the kind of trainer and the role of the players (e.g. goalkeepers, floaters, midfielders) also need to be considered.

At the introductory stage of sports learning, it is important that the skills and knowledge are taught gradually. SSGs must be developed from simple to complex tactical/technical aspects during primary and secondary education. Following Almond [2], it is recommended to introduce SSGs into pedagogical models, especially when using game-centred approaches, such as the Teaching Games for Understanding in $\mathrm{PE}$ or the Game Sense Approach in extracurricular sports training.

Finally, according to this author, the implication of the game index (obtained by GPAI) is a useful indicator to orientate teachers during the implementation of the games, as well as to follow an adequate progression of sessions, including all the contents required by the curriculum in an effective and holistic way.

\section{Conclusions}

The results presented in this article confirm that SSGs are an ideal context and pedagogical strategy to increase opportunities for participation among students. SSGs contribute to significant improvements in the physiological aspects (such as HR and distance travelled) as well as the tactical/technical knowledge (such as the effectiveness in decision-making and tech- nical execution) of students. The results show significant differences between PE and primary education pupils due to discrepancies in certain variables (such as the level of motivation, the kind of sport, previous skills, and respect for the rules), which should be taken into account when teachers or trainers decide whether to use SSGs in the different kinds of pedagogical models or approaches. Consequently, SSGs constitute a pedagogical tool to improve the performance of the students and to encourage the teaching/learning process of the teachers.

However, new investigations of the effects of SSGs are needed in other types of sports, such as net-wall games or fielding/run score games. A new line of investigation should be oriented towards comparing and analysing students' intrinsic motivation or fair play attitudes during SSGs, as well as those variables which can influence the intention to be more active (i.e. physical and sports engagement) [34]. In this sense, it will be also interesting to analyse the temporal evolution of the sports practice, tactical and technical intelligence, as well as the psychosocial variables presented in the sport learning process [35].

\section{Disclosure statement}

No author has any financial interest or received any financial benefit from this research.

\section{Conflict of interest}

The authors state no conflict of interest.

\section{References}

1. Roman JE, Aström P, Ferry M. Practical knowledge of preservice physical education teachers: content and influence of acculturation. J Phys Educ Sport. 2018; 18(1):114-126; doi: 10.7752/jpes.2018.01015.

2. Almond L. Rethinking teaching games for understanding. Ágora. 2015;17(1):15-25.

3. Clemente FM. Small-sided and conditioned games in soccer training: the science and practical applications. Singapore: Springer; 2016.

4. López-Fernández J, Sánchez-Sánchez J, Gallardo L, García-Unanue J. Metabolic power of female footballers in various small-sided games with different pitch surfaces and sizes. Sports. 2017;5(2):24; doi: 10.3390/ sports5020024.

5. Clemente FM, Lourenço Martins FM, Mendes RS. Developing aerobic and anaerobic fitness using smallsided soccer games: methodological proposals. Strength Cond J. 2014;36(3):76-87; doi: 10.1519/SSC.000000 0000000063.

6. Sarmento H, Clemente FM, Harper LD, Da Costa IT, Owen A, Figueiredo AJ. Small-sided games in soccer - a systematic review. Int J Perform Anal Sport. 
2018;18(5):693-749; doi: 10.1080/24748668.2018. 1517288 .

7. Ometto L, Vasconcellos FV, Cunha FA, Teoldo I, Souza CR, Dutra MB, et al. How manipulating task constraints in small-sided and conditioned games shapes emergence of individual and collective tactical behaviours in football: a systematic review. Int J Sports Sci Coach. 2018;13(6):1200-1214; doi: 10.1177/1747954 118769183.

8. Sgrò F, Bracco S, Pignato S, Lipoma M. Small-sided games and technical skills in soccer training: systematic review and implications for sport and physical education practitioners. J Sports Sci. 2018;6(1):9-19; doi: 10.17265/2332-7839/2018.01.002.

9. Práxedes Pizarro AP, García-González L, Moreno Cortés A, Moreno Arroyo MP, Moreno Domínguez AM. Application of an intervention program to improve tactical understanding in indoor football: a study conducted in an educational context [in Spanish]. Movimento. 2016;22(1):51-62; doi: 10.22456/1982-8918. 55024.

10. Harvey S, Jarrett K. A review of the game-centred approaches to teaching and coaching literature since 2006. Phys Educ Sport Pedagogy. 2014;19(3):278-300; doi: 10.1080/17408989.2012.754005.

11. Kirk D, Lamb CA, Oliver KL, Ewing-Day R. Fleming C, Loch A, et al. Balancing prescription with teacher and pupil agency: spaces for manoeuvre within a pedagogical model for working with adolescent girls. Curri J. 2018;29(2):219-237; doi: 10.1080/09585176.2018. 1449424.

12. Rojas-Inda S. Analysis of internal and external load in small games in young football players. Rev Int Med Cienc Act Fis Deporte. 2018;18(71):463-477; doi: 10.15366/rimcafd2018.71.004.

13. McLaren SJ, Macpherson TW, Coutts AJ, Hurst C, Spears IR, Weston M. The relationships between internal and external measures of training load and intensity in team sports: a meta-analysis. Sports Med. 2018;48(3):641-658; doi: 10.1007/s40279-017-0830-z.

14. Malone JJ, Lovell R, Varley MC, Coutts AJ. Unpacking the black box: applications and considerations for using GPS devices in sport. Int J Sports Physiol Perform. 2017;12(Suppl 2):S2-18-S2-26; doi: 10.1123/ ijspp.2016-0236.

15. Carrasco-Beltrán H, Reigal-Garrido RE, Ulloa-Díaz D, Chirosa-Ríos IJ, Chirosa-Ríos LJ. Effects of smallsided exercises on body composition and maximal oxygen uptake in adolescents [in Spanish]. Rev Med Chil. 2015;143(6):744-750; doi: 10.4067/S0034-988 72015000600007.

16. Holf J, Wisløff U, Engen LC, Kemi OJ, Helgerud J. Soccer specific aerobic endurance training. Bri J Sports Med. 2002;36(3):218-221; doi: 10.1136/bjsm.36.3.218.

17. Owen AL, Wong del P, McKenna M, Dellal A. Heart rate responses and technical comparison between small- vs large-sided games in elite professional soc- cer. J Strength Cond Res. 2011;25(8):2104-2110; doi: 10.1519/JSC.0b013e3181f0a8a3.

18. Atlı H, Köklü Y, Alemdaroğlu U, Koçak FÜ. A comparison of heart rate response and frequencies of technical actions between half-court and full-court 3-a-side games in high school female basketball players. J Strength Cond Res. 2013;27(2):352-356; doi: 10.1519/JSC.0b013e31 82542674.

19. Olthof SBH, Frencken WGP, Lemmink KAMP. Matchderived relative pitch area changes the physical and team tactical performance of elite soccer players in small-sided soccer games. J Sports Sci. 2018;36(14): 1557-1563; doi: 10.1080/02640414.2017.1403412.

20. Serra Olivares J, González Víllora S, García López LM. Comparison of the performance of soccer players aged 8-9 years old in two modified games 3 against 3 . Cuad Psicol Deport. 2011;11(2):77-91.

21. Bayer C. The teaching of collective sports games [in Spanish]. Barcelona: Hispano Europea; 1992.

22. Oslin JL, Mitchell SA, Griffin LL. The Game Performance Assessment Instrument (GPAI): development and preliminary validation. J Teach Phys Educ. 1998; 17(2):231-243; doi: 10.1123/jtpe.17.2.231.

23. Cohen J. Statistical power analysis for the behavioral sciences. New York: Lawrence Erlbaum Associates; 1988.

24. Cordova A, Villa G, Sureda A, Rodríguez-Marroyo JA, Sánchez-Collado MP. Physical activity and cardiovascular risk factors in Spanish children aged 11-13 years. Rev Esp Cardiol. 2012;65(7):620-626; doi: 10.1016/ j.recesp.2012.01.026.

25. Dellal A, Hill-Haas S, Lago-Penas C, Chamari K. Small-sided games in soccer: amateur vs. professional players' physiological responses, physical, and technical activities. J Strength Cond Res. 2011;25(9):23712381; doi: 10.1519/JSC.0b013e3181fb4296.

26. Hill-Haas SV, Dawson B, Impellizzeri FM, Coutts AJ. Physiology of small-sided games training in football: a systematic review. Sports Med. 2011;41(3):199-220; doi: 10.2165/11539740-000000000-00000.

27. Diaz del Campo DG, Gonzalez Villora S, Garcia Lopez LM, Mitchell S. Differences in decision-making development between expert and novice invasion game players. Percept Motor Skill. 2011;112(3):871-888; doi: 10.2466/05.10.11.25.PMS.112.3.871-888.

28. Morales Belando MT, Arias-Estero JL. Differences between the 7 vs. 7 and 4 vs. 4 game handball at school in relation to performance, perceived exertion and intention to be physically active. Retos. 2015;27(1):34-39.

29. Yiannaki C, Carling C, Collins D. Could futsal hold the key to developing the next generation of youth soccer players? Sci Med Football. 2018;2(1):71-74; doi: 10.1080/24733938.2017.1332422.

30. Balakrishnan M, Rengasamy S, Aman MS. Effect of teaching games for understanding approach on students' cognitive learning outcome. World Acad Sci Eng Technol. 2011;77(1):163-166. 


\section{HUMAN MOVEMENT}

C. Evangelio et al., 3 vs. 3 small-sided games at school

31. Serra-Olivares J, González-Víllora S, García-López LM. Effects of modification of task constraints in 3-versus-3 small-sided soccer games. S Afr J Res Sport Phys Educ Recreation. 2015;37(2):119-129.

32. Parlebas P. Games, sport and society. Lexicon of motor praxeology [in Spanish]. Barcelona: Paidotribo; 2001.

33. Aguilar Sánchez J, Martín Tamayo I, Chirosa Ríos LJ. The assessment in physical education through the "Game Performance Assessment Instrument” (GPAI) [in Spanish]. Estud Pedagog. 2016;42(2):7-19; doi: 10.4067/ S0718-07052016000200001.

34. Anguera MT. Introduction to monograph on observational data analysis. Anal Psicol. 2017;33(3):433-435; doi: 10.6018/analesps.33.3.270921.

35. Pic M. Performance and home advantage in handball. J Hum Kinet. 2018;63(1):61-71; doi: 10.2478/hukin2018-0007. 